\title{
PRÁTICAS E REPRESENTAÇÕES DA DITADURA MILITAR NA PROPAGANDA DE DESAPROPRIAÇÃO DA ITAIPU BINACIONAL
}

\author{
Catiane Matiello \\ Licenciada em História pela Universidade Estadual de Ponta Grossa. \\ e-mail: catimatiello@hotmail.com
}

RESUMO: A partir da década de 1970, com o início das obras da Usina Hidrelétrica de Itaipu Binacional, cerca de 40 mil pessoas, ao longo dos oito municípios brasileiros afetados pela formação do lago, começaram a viver o drama da expropriação, sendo aproximadamente 20 mil o número de desapropriados no Paraguai, num dos maiores processos migratórios da história contemporânea brasileira. O presente trabalho focaliza a trajetória das famílias expropriadas, marcada pelo desenraizamento social e por violências simbólicas, por meio da análise de propagandas relacionadas à Itaipu como representações do discurso do governo militar, direcionado à população desapropriada de suas terras. Dessa forma, acreditamos que a análise dessa documentação pode revelar a amplitude e a sofisticação dos discursos proferidos pelo governo sobre a Usina. Estes visavam, sobretudo, convencer os desapropriados e a opinião pública nacional sobre a "inquestionável" legitimidade de suas ações em torno da concretização do projeto. Ainda é possível observar a importância dos meios de comunicação para a ditadura assegurar o predomínio do seu projeto de desenvolvimento sobre outros, valendo-se de inúmeros e sofisticados recursos discursivos.

PALAVRAS-CHAVE: Itaipu Binacional; Ditadura militar; Expropriação. 
O objetivo principal da presente pesquisa consistiu na análise de propagandas relacionadas à Itaipu Binacional como representações do discurso dos governos militares direcionado à população desapropriada de suas terras para a construção da Usina. Procuramos identificar quais os aspectos que revelam o modelo de desenvolvimento defendido pela ditadura, quais os sujeitos diretamente envolvidos, como devem agir e como são identificados e interpelados pelo governo a partir do mapeamento de suas práticas sociais, políticas, culturais e econômicas. Especialmente, quisemos investigar que conflitos se manifestaram nesse processo e quais as soluções para resolvê-los apresentadas pelo governo militar em suas propagandas.

Portanto, a problemática visou interpretar algumas das representações sociais sobre a Usina Hidrelétrica de Itaipu, focalizando, por meio da propaganda, as estratégias discursivas do regime militar para atingir seu público-alvo. Dessa forma, acreditamos que a análise da documentação existente e ainda pouco explorada pode revelar a amplitude e a sofisticação dos discursos proferidos pelo governo para convencer os desapropriados e a opinião pública nacional sobre a "inquestionável" legitimidade de suas ações em torno da concretização desse projeto monumental.

A fase específica das desapropriações na região Oeste do Paraná ocorreu entre 1978 e 1982, período em que se verificou a ocorrência de expressiva propaganda relativa ao processo de desapropriação. Para contextualizar esse recorte, buscou-se compreender o panorama histórico da ditadura militar e especialmente de seus projetos econômicos, entre os quais se insere a Usina Hidrelétrica de Itaipu.

Dentro desse contexto, buscamos estudar alguns dos princípios que sustentaram o discurso dos militares, baseado na Doutrina de Segurança Nacional que pregava a "segurança e o desenvolvimento" do País, como fonte para a justificativa e execução dos grandes projetos de desenvolvimento econômico e de infra-estrutura do Brasil.

Segundo N. Habert, a hidrelétrica de Itaipu assumiu dimensões estratégicas, políticas e sociais, inserindo-se na euforia do "milagre econômico", que levava a acreditar que "até o ano 2000 o Brasil seria elevado à categoria de grande potência Mundial" (HABERT, 1996: 13). Este surto de otimismo sustentava-se na expansão do sistema capitalista, baseada, por sua vez, na exploração da classe trabalhadora, 
na consolidação do grande capital nacional e internacional e na entrada maciça de capitais estrangeiros na forma de investimentos e de empréstimos.

Ao contrário do que se tornou aparente, o projeto final de construção de Itaipu não ficou livre de polêmicas nos meios técnicos e políticos. Muitas foram as discussões, porém, as ditaduras militares no Brasil e no Paraguai silenciavam os possíveis questionamentos mediante um acentuado estreitamento dos canais formais de participação política e do afastamento da população civil, buscando a neutralização e mesmo o extermínio das forças de oposição não-consentidas ao regime (CERRI, 2000: 08).

A ditadura militar foi portadora de uma cultura tecnocrata. ${ }^{1}$ Esta visão, que valorizava a corrida em busca do progresso em prejuízo das diversidades culturais, sociais e notavelmente no caso de Itaipu, ecológicas, chegou ao seu termo ameaçando tradições, destruindo ecossistemas e reduzindo o homem a um simples obstáculo a ser removido para que a concretização de um empreendimento modernizador pudesse sobrevir.

O condicionamento dos expropriados à visão tecnocrática implicaria a reprodução das visões dominantes e, conseqüentemente, uma postura acrítica diante dos acontecimentos. Assim, os sujeitos tornar-se-iam mais próximos da condição de objeto de observação que da condição de sujeito, de acordo com a definição de Foucault, que o considera como um "ser que analisa criticamente a realidade, busca permanentemente o conhecimento e, eventualmente, transforma 0 real" (FOUCAULT, 1984).

Portanto, é a partir da década de 1970, com o início das obras, que os agricultores começam a viver o drama da expropriação. Ao longo dos oito municípios $^{2}$ afetados pela formação do lago, cerca de 40 mil pessoas foram desapropriadas, somente na margem brasileira, sendo aproximadamente 20 mil o número de desapropriados no Paraguai, num "dos processos mais radicais de diáspora ocorridos na história contemporânea" (RIBEIRO, 2002: 12).

\footnotetext{
${ }^{1}$ Em torno das teorias sobre o conceito de tecnocracia, ver o item sobre a tecnologia tecnoburocrática, do capítulo "O Estado-Cientista", CHATELET, François. História das Idéias Políticas. Rio de Janeiro: Jorge Zahar Ed., 2000, p.339.

${ }^{2} \mathrm{Na}$ época da construção da Hidrelétrica de Itaipu eram oito os municípios diretamente afetados, sendo eles: Foz do Iguaçu, São Miguel do Iguaçu, Medianeira, Matelândia, Santa Helena, Marechal Cândido Rondon, Terra Roxa e Guairá. Depois, alguns distritos foram se desmembrando, contabilizando hoje 15 municípios.
} 
Desde 1975, o governo federal prometia pagar um preço justo pela indenização, como pôde ser verificado mediante a ampla propaganda veiculada na região, de acordo com a documentação existente no Centro de Documentação da Itaipu Binacional, em Foz do Iguaçu. Porém, em 1978, eram poucas as famílias que haviam recebido as indenizações (FERNANDES, 2000: 65), sendo que, ainda, por um preço muito abaixo do esperado. Algumas famílias foram transferidas para projetos de colonização no Mato Grosso, ou no Norte do País, como foi o caso do Projeto Pedro Peixoto, no Acre. Essa situação fez com que, no mesmo ano de 1978, as Igrejas Luterana e Católica (por meio da CPT (Comissão Pastoral da Terra), bem como alguns sindicatos de trabalhadores rurais começassem um trabalho de organização nas comunidades, formando, em 1980, o Movimento Justiça e Terra, numa luta contra a política do governo. O Movimento agiu promovendo a organização das famílias, mediante espaços de conscientização, bem como auxiliando nas negociações com o governo, conquistando o aumento do preço das indenizações e dois assentamentos nos municípios de Arapoti e Toledo (FERNANDES, 1987: 22-23).

Em 1981, ainda havia em torno de 500 famílias que perderam suas terras, seus empregos, suas casas. Iniciou-se um processo de resistência e os camponeses expropriados passaram a formar movimentos localizados. Assim, nos anos de 1982 e 1983 surgiram vários movimentos sociais em diversas regiões do Estado. A CPT organizou essas famílias e começou a cadastrar outras que, expulsas, estavam interessadas em lutar por terra no Paraná. Em menos de um ano havia mais de 6 mil famílias cadastradas, que passaram a formar o Mastro (Movimento dos Agricultores Sem Terra do Oeste do Paraná).

A população desalojada por Itaipu ainda superava o processo de migração sofrido quando saíram dos estados do Rio Grande do Sul e de Santa Catarina em busca de terras no Paraná. Essas pessoas também carregavam consigo, de maneira ainda latente, as histórias de seus pais e avós vividas também durante um processo migratório, em fins do século XIX e início do XX, quando abandonaram seus países de origem, na Europa, para vir fazer a América (FAUSTO, 1998).

O agricultor Marcelo Barth, na época das desapropriações realizadas por Itaipu, dizia: 
Estamos aqui há mais ou menos 15 anos, desbravando, plantando e colhendo, contribuindo para a grandeza desta terra. Agora vêm nos dizer que vamos ser sacrificados. Como se não bastassem nossas mãos calejadas, as costas encurvadas, as frontes enrugadas. Como se não bastasse surpreender tantas vezes nossa esposa chorando por falta de remédios, de comida, de tudo. Como se não bastasse ter ainda vivo na memória o choro de mães que perderam filhos por falta de dinheiro para irem ao médico.

Desde criança estou vendo que o povo que trabalha, sofre e produz o alimento para saciar a fome do mundo tem na sua própria mesa cada vez menos para comer. Um pedaço de pão cada vez menor para os pobres e o crescente desperdício de um grupo de privilegiados eis aí uma verdadeira afronta à nossa concepção cristã. Felizmente, depois de sofrer por muito tempo na própria carne os horrores dessa escravidão branca, os agricultores estão tomando consciência da grande força que têm na união. Os agricultores estão despertando e vão fazer valer, na força de sua união, o direito à terra, o direito a uma vida decente e, sobretudo, o direito a uma indenização justa quando o governo requer as suas propriedades. (MAZZAROLLO, 2003: 42)

Por meio da fala desse agricultor, percebemos como ele recorre a uma memória até então subterrânea (POLLACK, 1989) para argumentar contra o processo das indenizações, criando uma representação de uma cultura de resistência ante as relações de poder impostas pela ditadura militar no curso da implantação de seus projetos econômicos.

Para iniciarmos a análise dos textos partimos de algumas questões norteadoras, tais como buscar identificar a que sujeito pertence esta fala, de que forma ele se apresenta e a quem a dirige e que imagem este sujeito elabora a respeito de seu interlocutor. E, ainda, quais são os termos e os recursos utilizados para transmitir essas visões de quem fala e quem ouve.

A campanha foi organizada e planejada pela Abrap S.A. (Aliança Brasileira de Propaganda), agência publicitária de São Paulo que posteriormente forneceria o projeto publicitário a uma agência paraguaia para que, após as devidas adaptações, fosse também colocada em prática no país vizinho.

Mediante o Centro de Documentação da Itaipu Binacional, ${ }^{3}$ tivemos acesso aos documentos da Abrap relacionados à "estratégia de criação" da campanha

${ }^{3}$ O Centro de Documentação da Itaipu Binacional possui um rico acervo de documentos que, além das propagandas, inclui documentação externa e interna sobre a construção, manutenção e operação da Usina desde seu início, recortes de jornais e revistas, com artigos, reportagens e divulgações sobre a empresa desde 1974, tanto no âmbito nacional e regional quanto internacional. 
publicitária. A campanha estava dividida em filmes para TV e cinema, jingles e spots ${ }^{4}$ regionais, folhetos e pôsteres que seriam distribuídos localmente. Numa segunda fase, "extra local", os meios utilizados para distribuir as propagandas seriam os jornais, as revistas nacionais, a televisão e o cinema.

Além da tentativa de tornar mínimos os choques no processo de expropriação dos agricultores, a campanha também buscava aconselhá-los para que não tratassem da venda de suas propriedades com intermediários, que poderiam aproveitar a situação para fazer especulações imobiliárias.

Desse modo, na fase local, em todas as criações possíveis "seriam utilizados elementos que (...) exerçam carisma sobre os grupos alvos; (...) usaríamos elementos difundidos naquele contexto regional: duplas caipiras (Tonico e Tinoco), cantores (Teixeirinha), locutores e/ou animadores de rádio". ${ }^{5}$

Os folhetos e os pôsteres, que tinham como objetivo atingir um público mais restrito à população da futura área alagada, eram orientados pelos seguintes itens:

“(...) colocações bem mais acessíveis mantendo a preocupação de ajustamento de linguagem; (...) parte do visual desse folheto seria estabelecido a partir dos personagens que através dos demais veículos difundiriam as mensagens didáticas. (...) Utilizando personagens (reforço visual de atração) didáticos os posters levarão mensagens objetivas facilmente assimiláveis (...)". 6

O projeto de criação das propagandas como um todo demonstra a enorme abrangência e a sofisticação da campanha concebida, utilizando-se de vários meios de comunicação disponíveis, como também de variadas formas e diversos gêneros de abordagem contida nas mensagens. Esses fatores destacados indicam o peso e a importância que as ações governamentais transferiam para a publicidade.

Porém, como a campanha visava tanto ao alcance local quanto ao nacional, o que implica públicos e gostos diferenciados, a propaganda assumiu algumas

${ }^{4}$ Designação usual de mensagem publicitária breve veiculada em rádio ou televisão, sendo mais utilizado para rádio; em TV se utiliza geralmente o termo comercial. Pode ser tanto um comercial como uma mensagem institucional. Sobre isso ver: SILVA, Júlia Lúcia de Oliveira Albano da. Rádio: oralidade mediatizada o Spot e os elementos da linguagem radiofônica. São Paulo: Annablume, 2003.

${ }^{5}$ ABRAP S.A. "Estratégia de criação-considerações gerais" Rolo/filme: 0375F de $16 \mathrm{~mm}$, fotograma n.. 0228. Centro de Documentação de Itaipu Binacional.

${ }^{6}$ ABRAP S.A. "Estratégia de criação-considerações gerais" Rolo/filme: 0375F de $16 \mathrm{~mm}$, fotograma n.. 0229. Centro de Documentação de Itaipu Binacional. 
características distintas, tendo em vista esse aspecto. No texto seguinte, os criadores da propaganda sugerem como narrador o ator Tarcísio Meira:

Olá pessoal.

O assunto é a usina de Itaipu.

Eu estou aqui prá dizer algumas coisas do trabalho que vai ser feito na região que será atingida pelo represamento das águas. Vejam só: Itaipu pagará um preço justo pelas terras que ela precisa comprar. Vai orientar os donos de terras que não possuem documentos para que obtenham seus registros de propriedade. Quando eu digo terras, eu também quero dizer: fazendas, sítios, plantações, casas. Enfim, todo tipo de propriedade e benfeitorias que existam na região. E tem mais, o pessoal vai poder continuar trabalhando nas terras por muitos anos ainda. Até 1982, para quando está previsto o represamento das águas.

Ninguém foi esquecido. Até as matas e os bichos serão levados para outro lugar. As árvores vão ser replantadas, e os animais transferidos para áreas onde poderão viver tranqüilos.

Como você vê, o pessoal de Itaipu não brinca em serviço. Por isso fique tranqüilo. Confie e receba bem o pessoal da Itaipu. É gente que está aí prá ajudar."7

Além das visões construídas pelo governo a seu próprio respeito e a respeito de quem ouve as mensagens, identificadas mediante uma relação paternalista, os argumentos do discurso que podemos destacar ocorrem em relação aos pontos de conflitos ou problemas que eventualmente colocariam as pessoas contra o projeto. Alguns desses problemas consistiriam nas polêmicas em torno do valor pago pelas propriedades, a questão da obtenção de registro de terras não legalizadas e questões ambientais e ecológicas. A apresentação dessas situações, com sua seqüente explicação sobre como a Itaipu irá proceder, se dá de forma pretensamente "didática".

Ou seja, o conteúdo do texto, além de reafirmar a competência dos responsáveis pela construção da Usina de Itaipu e sua idoneidade, o que garantiria um processo de desapropriação justo e tranqüilo, trata também de rebater possíveis críticas ao projeto relativas a questões ambientais.

Podemos observar que a propaganda de construção da Usina deseja inspirar confiança tanto para aqueles que perderão algo de forma direta quanto para a população do restante do País; logo, a estratégia empregada para este fim não

7 ABRAP S.A. "Estratégia de criação-considerações gerais" (filme tv-cinema 60") 16/06/1976. Rolo/filme: $0375 \mathrm{~F}$ de $16 \mathrm{~mm}$, fotograma no. 0252. Centro de Documentação de Itaipu Binacional. 
consistiu em apenas afirmar de forma enunciada o "pessoal da Itaipu" como "gente que não brinca em serviço", mas também, em utilizar-se de registros semióticos nãoverbais, aqui identificados por meio da escolha de um ator nacional, portador de carisma diante do público em geral. ${ }^{8}$

A seguir, selecionamos um trecho do texto que caberia à divulgação mediante pôsteres e panfletos. De acordo com as orientações, o texto viria acompanhado das fotos de três agricultores da região citados:

"Severino Assunção - plantador de soja no município de Guaíra.

Benedito Oliveira - plantador de milho no município de Matelândia.

Antenor Lima - plantador de menta no Município de Santa Helena.

Plantando esses homens vão ajudar a construir a maior usina hidrelétrica do mundo: Itaipu $(\ldots)$

Uma área de $1.400 \mathrm{~km}^{2}$ (cerca de 58.000 alqueires entre o Brasil e o Paraguai) vai ser inundada para represamento das águas que irão gerar 75 milhões de quilovates hora por ano.

Esses homens vão começar a receber a justa indenização pelas suas terras e todas as benfeitorias nelas existentes, inclusive lavouras plantadas. Mas não vão abandonar de imediato essas lavouras. Pela primeira vez na história os proprietários vão ser pagos à vista e entregar suas propriedades a prazo. Isto é, até a data do represamento das águas, previsto para 1982, continuarão em suas terras, cultivando suas lavouras, produzindo para o interesse do país e para o abastecimento da própria região.

Itaipu adotou essa filosofia pioneira, que inclui o contato direto, sem intermediário de nenhuma espécie, com cada um dos 10.500 proprietários brasileiros e paraguaios da região. Tanto proprietários rurais, como urbanos.

E com eles colaborará ainda por todos os meios e modos, desde a legalização de títulos de propriedade, quando for o caso, até a locomoção e a instalação em áreas adjacentes.

Um vasto plano de comunicação e informações foi elaborado e está em plena execução na região, a fim de enfrentar um desafio tão grande quanto o da própria obra.

${ }^{8}$ A telenovela, herdeira das novelas de rádio, transformou-se em um dos programas mais populares da televisão brasileira, projetando artistas como Tarcísio Meira para o meio da cultura de massas. Além disso, em 1972 o ator interpretou Dom Pedro I no filme "Independência ou Morte", aumentando sua fama e destaque nacionais. Por meio de um fenômeno verificado habitualmente no público, relacionado à atribuição da identidade encenada ao ator, este acaba tornando-se estigmatizado pelas características de seu personagem. 
Tudo para que homens como Severino, Benedito e Antenor tenham a máxima tranqüilidade em sua tarefa de continuar produzindo e, assim, mais do que com a cessão de suas terras possam ajudar a construir a maior usina hidrelétrica do mundo."9

Podemos ressaltar algumas das noções implícitas neste discurso do governo. A primeira seria a da parceria/contribuição dos expropriados na "construção da maior usina hidrelétrica do mundo". Outra noção é a de que não se trata mais do ator famoso informando sobre o que vai acontecer, mas sim do sujeito comum sendo apresentado como beneficiado. Há, ainda, a questão da credibilidade e da eficiência técnica presentes em trechos como: "um vasto plano de comunicação e informações foi elaborado e está em plena execução na região, a fim de enfrentar um desafio tão grande quanto o da própria obra"; além disso, deve-se destacar a visão autoritária presente neste discurso, que atribui papéis aos sujeitos, ficando cada qual responsável pelo cumprimento de suas tarefas na sociedade.

No caso desta propaganda, a utilização de fotos de três agricultores da região devidamente identificados, acompanhadas de notas com o tipo de produtos que plantam e sobre onde residem, pode servir como uma ferramenta que expressa os valores materiais e mesmo culturais em sintonia com os do restante da população afetada pela usina. A propaganda afirma claramente que se Severino, Benedito e Antenor podem ficar tranqüilos e "continuar produzindo para o interesse do país e para o abastecimento da própria região", essa também pode vir a ser a reação das 8 mil famílias desapropriadas. Deste documento, ainda podemos elaborar uma análise em que a Usina Hidrelétrica de Itaipu é representada como um monumento à grandeza do povo brasileiro. Antes que os expropriados dêem a sua contribuição definitiva para este grande monumento - a "maior usina hidrelétrica do mundo" eles ainda terão a chance de dar continuidade à sua atual contribuição à nação, que é produzir alimentos e abastecer o País.

Com base nestas análises, pudemos constatar que as propagandas tiveram importante papel no conjunto de representações que convenceram as pessoas, não apenas localmente, mas também em termos nacionais, de que a construção da maior usina hidrelétrica do mundo era motivo de orgulho, constituindo-se num símbolo da competência de seus governantes, que proporcionavam ao País a

\footnotetext{
${ }^{9}$ ABRAP S.A. "Estratégia de criação - considerações gerais" 01/jul/1976. Rolo/filme: 0375F de 16mm,
} 
integração a um contexto mundial de progresso e tecnologia, contradizendo a realidade concreta das 40 mil famílias que se viram obrigadas a abandonar suas terras. Torna-se ainda possível observar a importância dos meios de comunicação para a ditadura assegurar o predomínio do seu projeto de desenvolvimento sobre outros, valendo-se de inúmeros e sofisticados recursos discursivos.

Dessa forma, a Usina de Itaipu aparece associada às representações de cultura e poder da época da ditadura militar. Representações carregadas das idéias de nacionalismo, gigantismo, modernização, tecnologia e progresso, caracterizandoa como um dos seus "projetos faraônicos", vindo a contribuir para a disseminação da ideologia de "Brasil Grande". Mediante cada etapa da construção da usina, uma cultura tecnocrática de eficiência e de competência do governo deveria ficar explícita nas representações produzidas pelo poder para se legitimar.

\section{REFERÊNCIAS BIBLIOGRÁFICAS}

CERRI, Luis Fernando. Ensino de História e nação na publicidade do Milagre Econômico. Brasil: 1969 -1973. Campinas, 2000. Tese (doutorado) - Universidade Estadual de Campinas.

FERNANDES, Bernardo Mançano. A formação do MST no Brasil. Petrópolis, RJ: Vozes, 2000.

FAUSTO, Boris. História do Brasil. São Paulo: Editora da Universidade de São Paulo: Fundação do Desenvolvimento da Educação, 1998.

FOUCAULT, M. A microfísica do poder. Rio de Janeiro: Graal. 4. ed., 1984.

HABERT, Nadine. A década de 70. Apogeu e crise da Ditadura Militar Brasileira. 3. ed. São Paulo: Editora Ática, 1996.

POLLAK, Michel. "Memória, esquecimento, silêncio". Estudos Históricos (3): Memória. Rio de Janeiro: Associação de Pesquisa e Documentação Histórica, v. 2, n. 3, 1989, pp. 3-15

MAZZAROLLO, Juvêncio. A Taipa da Injustiça. São Paulo: Edições Loyola, 2003.

RIBEIRO, Maria de Fátima B. Memórias do concreto: vozes na construção de Itaipu. Cascavel: Edunioeste, 2002.

fotograma n. 0226. Centro de Documentação de Itaipu Binacional. 
